AARP INTERNATIONAL THE JOURNAL

VOLUME $11-2018$ EDITION

Real Possibilities

\title{
Reflections from Japan
}

By Debra Whitman 
Reflections from Japan

By Debra Whitman

It is a beautiful morning at Kotoen. Dozens of four and five-year-olds bow and septuagenarians, octogenarians, and even some centenarians return the courtesy. Together they begin to stretch and sing to an exercise program called "Rajio Taisou," introduced in Japan in 1928. When the music stops, the youngsters run into the welcoming arms of the "grandpas" and "grandmas." Young and old walk away hand in hand ready to face the day.

I think to myself: This is why I came to Japan. 


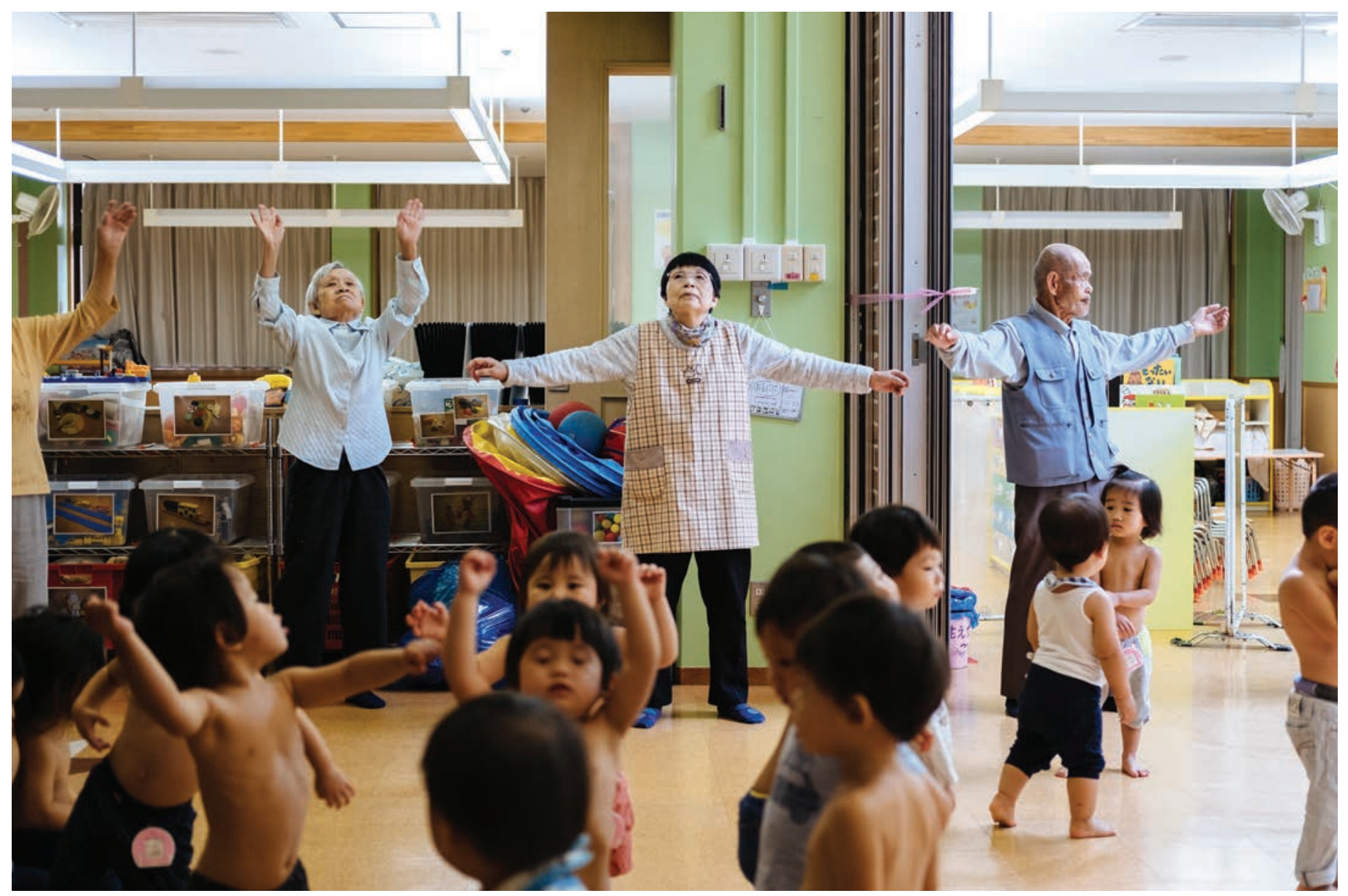

Seniors and children stretching to Rajio Taisou at Kotoen.

$\mathrm{A}$ $s$ a researcher and a former policymaker, I have long studied from afar how the oldest country in the world has innovated and adapted. But I wanted to personally see models of caregiving, commerce, and technology so that I could truly understand their benefits and limitations. So in the Fall of 2017, I traveled with Bradley Schurman, Director of Global Partner Engagement at AARP International, on a learning tour to seven different locations in four days. I left Japan both exhausted and inspired.

My favorite stop was Kotoen. Located on the outskirts of metropolitan Tokyo, Kotoen is both a long-term care community and a day care center and is a perfect example of the advantages of linking the generations. As we walked through the facility, we saw children interacting with wheelchair-bound elders and grandpas reading to their boys and girls. Importantly, we learned about the key role played by a trained and supported staff that worked seamlessly with them all.

We knew Japan was an innovator in the use of caregiving robots, so we wanted to see what high tech could do to help a high-touch industry. We spent an afternoon at Motherth, a continuing care community, owned by Toyota, which provides services ranging from intensive nursing care to independent living to adult daycare. We saw how cameras and sensors were used 
to monitor residents in their rooms and apartments. Staff members were busy responding to these alerts, which gave residents confidence that they would be found in an emergency.

Motherth also used robots as caregivers and entertainers. The Smile Baby robot was developed for people with dementia. Her soft body and unfinished face allows users to imagine the features of a baby they may have known in the past. The doll is also interactive. Hold the baby correctly and she coos and laughs and her cheeks get red. But hold the baby incorrectly and she lets out a lifelike cry - with lighted tears running down her face. Monami, another robot, is used to entertain the residents and does a passable Flamenco.

But as we continued our tour we found that sometimes the simplest technology could have the greatest impact on a resident's daily life. For example, bathing can be stressful both for a resident who is wheelchair bound and for the staff member who needs to safely maneuver the elder into a bathtub or shower. At Motherth, an aide wheeled a resident into a tiled room, easily transferring them to another chair and into a spaceship-like tub where the water enveloped the seated bather. In this space, bathing goes from being a difficult chore to a comfortable and refreshing experience.

While advances such as the bathing tub and a variety of robots that interact with patients may well become more commonplace in the future, we came away from our visits to several nursing homes continuing to believe that technology cannot take the place of intensive human touch. When people need a lot of care, sensors and entertainment simply are not enough. In Japan and the rest of the world, a highly trained and engaged staff turns out to be the key ingredient of any quality care environment.

PHOTOS

Learning about Cyberdyne's robotic exoskeleton, HAL; visiting the Omiya Bonsai Art Museum in Saitama; and taking a tour of a Care Lawson

location to learn how the convenience store chain has adapted to the senior market.
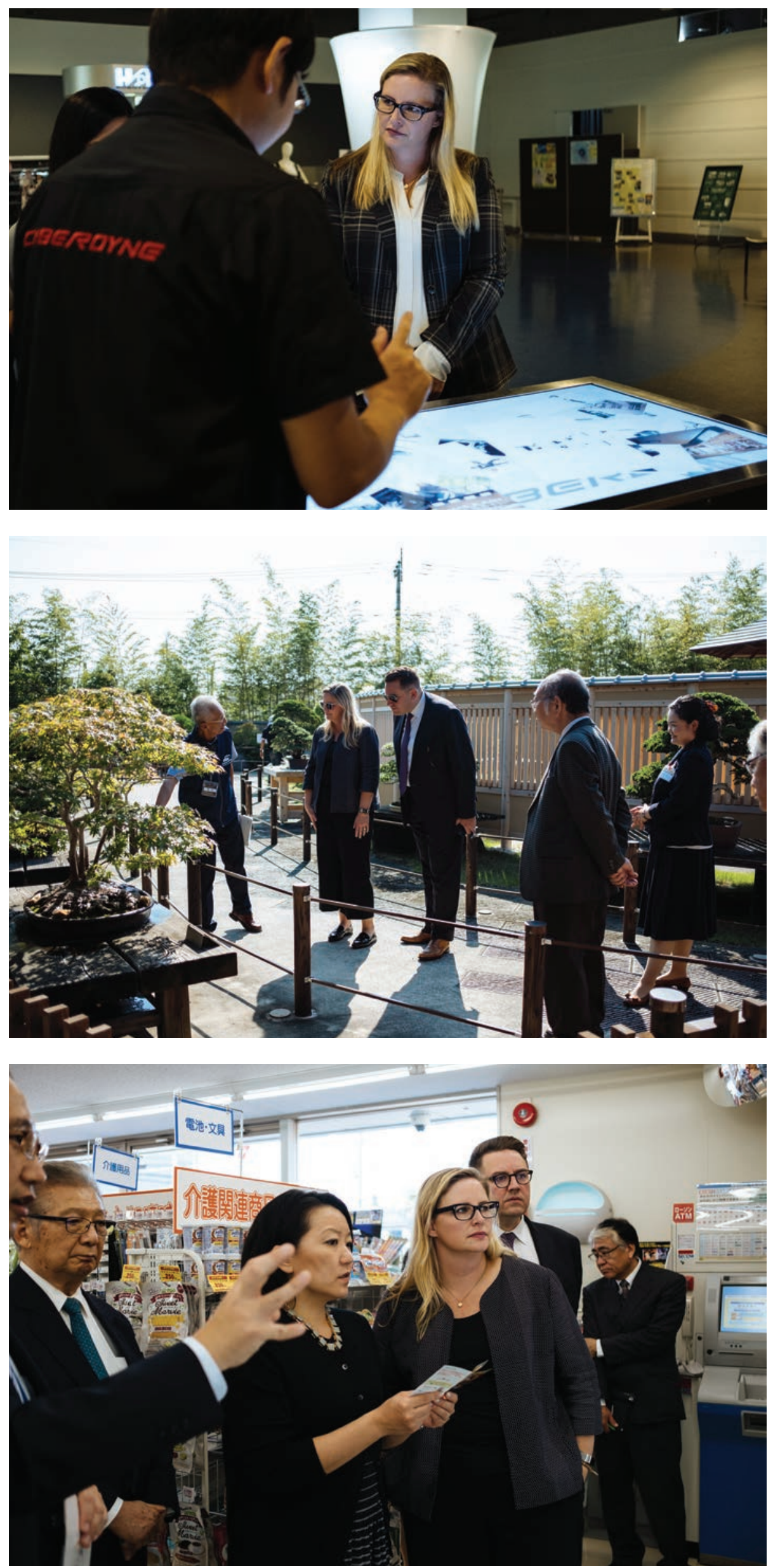


\section{"I left Japan knowing that I had only seen a fraction of the innovation and adaptation that is happening across the country. At AARP, we strive to import innovation and share ideas with the global community so we can all learn from best practices."}

We saw other examples of how Japanese companies have stepped up to the challenge of meeting the needs of an older population that lives independently in the community.

An aging population is transforming both the corner store and the large shopping mall. At Lawson's eight Care Lawson stores, you can buy the traditional fare available at any convenience store - milk, bread, beer, and chips. But these corner stores have been specifically adapted to meet the needs of their older clientele. They've widened the aisles and added a variety of products geared to older consumers - such as adult diapers and cane tips. Lawson's also packages ready-to-heat single serve meals and added labels that provide information about how easy or difficult the food will be to chew. These may seem like small things - but they mean a lot to older adults who normally must hunt for the products they need on a daily basis.

We found similar thought had gone into the Aeon shopping mall we toured. Like Lawson, Aeon is a full-service store with products that appeal to young and old. Aeon has adapted several of its malls specifically for Japan's aging population. We were pleased to see that specific personalized products and services were front and center - not hidden away in a corner.

As we walked on the fourth floor we came across probably the largest display of canes I'd certainly ever seen. Some were colorful, some had patterns, some were simple. But instead of hiding them away, the canes were displayed more like fashion accessories, not medical devices.

The Aeon developers also offer a range of programs that enable older adults to be part of the community and to have a warm, safe place to gather with their friends and make new ones.

The top floor, which originally housed a roller rink, includes a bookstore, café, activity rooms, and a health center. It features exercise classes that cater to young and old and a walking track where people can earn points and discounts for completing a lap.

I left Japan knowing that I had only seen a fraction of the innovation and adaptation that is happening across the country. At AARP, we strive to import innovation and share ideas with the global community so we can all learn from best practices. Our trip, this Journal, and our global research agenda are all ways that together we can benefit from and build on Japan's groundbreaking example. $\bullet$

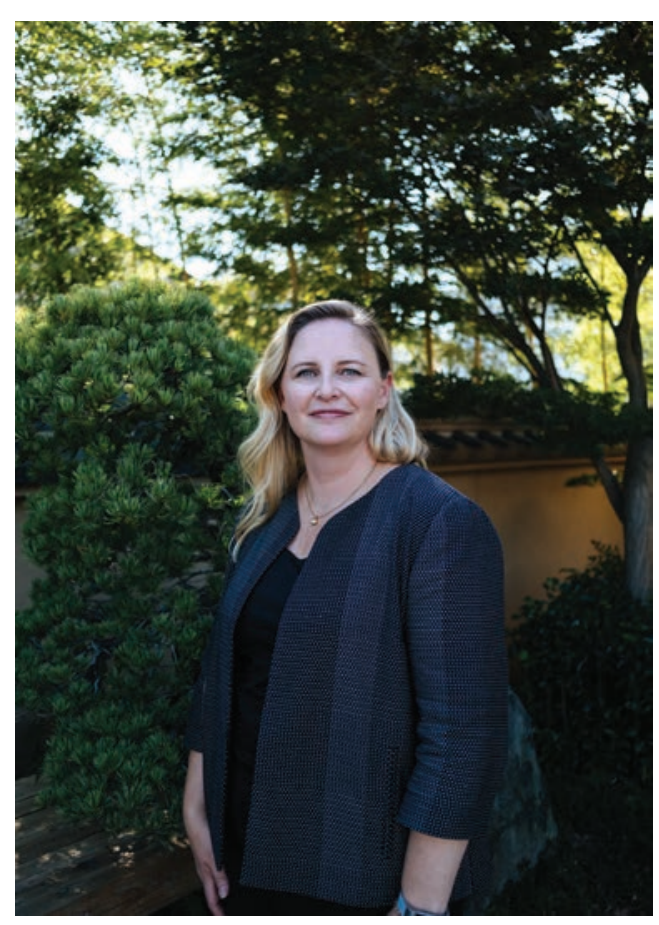

Debra Whitman

EXECUTIVE VICE PRESIDENT \& CHIEF PUBLIC POLICY OFFICER, AARP 
AARP International engages global stakeholders to spark solutions that strengthen communities, protect the vulnerable and enable people around the world to pursue their goals and dreams. Working with governments, civil society and the private sector, we are focused on enhancing the quality of life for people as they age. We serve as the global voice for AARP, a social change organization with a membership of more than 37 million.

THE JOURNAL ONLINE

aarpinternational.org/journal

AARP INTERNATIONAL ONLINE

aarpinternational.org

FACEBOOK

facebook.com/aarpintl

TWITTER

@aarpintl

CONTACT

AARP International

601 E Street, NW

Washington, DC 20049

United States

T +1 2024342398

E international@aarp.org

AARP International: The Journal is a publication of AARP. The views expressed herein do not necessarily represent policies of AARP and should not be construed as endorsements. The mention of a product or service herein is solely for information to our readers and may not be used for any commercial purpose. AARP, which was established in 1958, is a nonprofit, nonpartisan organization with tens of millions of members ages 50 and older. State offices are located in all 50 states, the District of Columbia, Puerto Rico, and the Virgin Islands.

January 2018

()2018, AARP

Reprinting with permission only. 